\title{
Detección del virus de la Hepatitis A en dos muestras de agua del Río Sechura, usando transcriptasa-reversa PCR en tiempo real.
}

\author{
Detection of Hepatitis A Virus in two water samples from Sechura river by using Real-Time Quantitative \\ Reverse Transcription PCR.
}

Marcos A ${ }^{1}$, Gómez-Sánchez $\mathrm{M}^{1}$, Hung A ${ }^{1}$.

\section{RESUMEN}

El Virus de la Hepatitis A (VHA) es un patógeno de transmisión fecal-oral, y el agua es un medio importante para su diseminación. El Río Sechura (Piura, Perú) desemboca al mar y representaría una fuente de contaminación a las playas Chulliyachi, San Pedro y San Pablo en donde se extraen moluscos bivalvos. Objetivos: Detectar VHA en muestras de agua del río Sechura mediante técnicas moleculares. Métodología: Se recogió en total 24 muestras de agua en tres puntos geográficos del río Sechura, en intervalos de cada 15 días durante 4 meses (de mayo a setiembre de 2013). Cada muestra se trasladó en botellas estériles de 1 litro. A cada botella se le realizó un proceso de concentración de virus en agua, luego extracción de ARN, y RT-PCR en tiempo real. Resultados y Conclusiones: Dos muestras $(2 / 24,8.3 \%)$ resultaron positivas a VHA. Este es el primer reporte de presencia de VHA en agua de río en el Perú.

Palabras clave: Virus de la Hepatitis A, RT-PCR en tiempo real, Río Sechura, agua.

\begin{abstract}
Hepatitis A virus (HAV) is a fecal-oral transmitted pathogen, and water is an important transmission way. This study considered a possible role in the HAV contamination of aquaculture areas by the Sechura River (Piura, Peru). In addition, this river gets into the sea and represents a source of contamination to Chulliyachi, San Pedro and San Pablo beaches where bivalve mollusks are collected. Objective: To detect HAV in waters of Sechura River by using molecular techniques. Methodology: Twenty four samples were collected from three different spots of the river. The samples were taken every two weeks during four months (from May to September 2013), these were transferred in 1 L sterile bottles to the Laboratory, then they were analyzed by a process of concentration of virus in water, thereafter RNA extraction and real time RT-PCR. Results and Conclusion: Two samples (2/24, 8.3\%) were positive to HAV. This is the first report of presence of HAV in river waters in Perú.
\end{abstract}

Key words: Hepatitis A virus, real time RT-PCR, Sechura river, water.

\section{INTRODUCCIÓN}

El Virus de la Hepatitis A (VHA) es un agente infeccioso importante para la salud pública a nivel mundial; endémico en países con recursos limitados como el Perú y de alta morbilidad en países desarrollados según la Organización Mundial de la Salud (OMS, 2008).
VHA es un virus ácido ribonucleico (ARN) no encapsulado de la familia Picornaviridae, de 27 $\mathrm{nm}$ que produce 1.4 millones de casos anuales en todo el mundo en forma de epidemias que recurren cíclicamente y su prevalencia se encuentra relacionada con las condiciones socioeconómicas, higiénico sanitarias y hacinamiento de una determinada región debido a la transmisión fecal-oral de este virus (Cuthbert, 2001 ; Restrepo y Toro, 2011).

\footnotetext{
Facultad de Medicina Veterinaria y Zootecnia UPCH
} 
En mayo de 2011, el Instituto Tecnológico de la Producción (ITP) reportó muestras de bivalvos extraídos de la bahía de Sechura positivas a VHA mediante la técnica de RT-PCR en tiempo real. (Monitoreo de la Bahia de Sechura). Luego, el 11 de abril de 2012, la dirección regional de Salud de Piura reportó un brote. (Reporte Semana Epidemiológica $\mathrm{N}^{\circ} 13$ DIRESA Piura, 25-31.03.2012)

Por otro lado, en 1999 y 2008 ocurrieron dos brotes de Hepatitis A en Valencia, España que fueron asociados con coquinas (Donax spp) congeladas importadas de Perú lo que provocó que se suspendan las importaciones de estos mariscos desde el Perú hacia la Unión Europea (UE, Pintó et al., 2009). Además del impacto sanitario, el agravio económico de este brote de hepatitis fue de USD\$ 4 millones de dólares sólo por el producto inmovilizado, y las pérdidas derivadas de la prohibición de la UE lograron quebrar el sector acuicultor peruano (Pintó et al., 2009).

Se ha detectado VHA en agua de mar y también en ríos (Rose et al., 2009; De Paula et al., 2007), agua de bebida (Ali et al., 2004; Kittigul et al., 2005). Existe evidencia de que VHA es transmitido por agua gracias a su estabilidad en ella, lamentablemente, el largo periodo de incubación del VHA y la ausencia de una prueba accesible y fácil para detectar VHA en agua hacen que esta vía de transmisión sea difícil de reconocer (Cuthbert, 2001).

Las muestras ambientales de agua contienen bajas concentraciones de virus que deben ser concentradas a tal punto, que permita una detección eficiente, por lo que existe una muy amplia variedad de técnicas de concentración viral en muestras de agua, que incluyen el uso de mayores volúmenes, lo cual es esencial para algunas aguas con niveles bajos de contaminación, como en agua de bebida o de mar (Ali et al., 2004; De Serres, 1999). Sin embargo, un estudio demostró que la concentración de los virus de una muestra muy grande puede ser contraproducente para ciertos tipos de muestras, porque los inhibidores se reconcentran (Gregory et al., 1999).

Un método para detectar VHA en muestras de agua ambientales se basa en la amplificación de una porción del genoma utilizando la reacción en cadena por la polimerasa -transcriptasa reversa (RT-PCR) en tiempo real. Este es uno de los métodos más sensibles para inspecciones virales en agua (De Paula et al., 2007; Kittigul et al., 2005 ; Tsai et al., 1993).
En aguas del Río Sechura (Piura, Perú) se realizan diversas actividades como pesca, lavado de conchas de abanico. Sin embargo, el depósito de basuras, desmontes y desagues en este río, representaría una potencial vía de transmisión de VHA. Además, el Río Sechura desemboca al mar en las playas Chulliyachi, San Pedro y San Pablo, donde se ubican los principales centros de repoblamiento y cultivo de moluscos bivalvos, representando una posible fuente de contaminación a los moluscos bivalvos que ahí se producen (Cavero y Rodríguez 2008 ; Acuña et al., 2006).

El objetivo del estudio fué detectar VHA en muestras de agua del río Sechura mediante la técnica de RT-PCR en tiempo real.

\section{MATERIALES Y MÉTODOS}

\section{Control positivo del virus}

Se colectaron 4 muestras de heces de niños diagnosticados con hepatitis A mediante la prueba de ELISA en el Instituto Nacional de Salud del Niño en Lima. Las muestras se transportaron con hielo para su análisis en el laboratorio usando la técnica de RT-PCR tiempo-real para la confirmación de la presencia del virus y luego usarlas como control positivo.

\section{Método de concentración de virus en muestras de agua}

Se empleó el protocolo de Baylor (Atmar et al., 1995; Da Silva et al., 2007) y $40 \mathrm{ml}$ de muestra de agua de río. Brevemente, se añadió $10 \mathrm{ml}$ de solución de polietilenglicol (PEG) 8000 (Sigma Aldrich, USA) al $50 \%$ a los $40 \mathrm{ml}$ de la muestra y se dejó en agitación durante una noche a $4{ }^{\circ} \mathrm{C}$. Luego se centrifugó usando una Z36HK Super Speed Centrifuge (Labnet) a 4000 revoluciones por minuto (RPM) durante 90 minutos a $4^{\circ} \mathrm{C}$ para precipitar los virus. El pellet se disolvió en $3 \mathrm{ml}$ de agua estéril (Agua DEPC,Sigma) con $1 \mathrm{ml}$ de tamón PK ( $2 \mathrm{ml}$ de Tris $\mathrm{HCl} 2 \mathrm{M}, 4 \mathrm{ml}$ de EDTA 0.5M, $20 \mathrm{ml}$ de Sodium Dodecyl Sulfate al 10\%,74 $\mathrm{ml}$ de agua estéril) $4 \mathrm{X}, 40 \mu \mathrm{l}$ de proteinasa K (Roche, Alemania, 20 $\mathrm{mg} / \mathrm{ml})$, y $4 \mathrm{ml}$ de fenol:cloroformo:agua (68:18:14). Luego, se homogenizó por 1 minuto, se centrifugó a $4^{\circ} \mathrm{C}$ por 5 minutos a $4000 \mathrm{RPM}$, se añadió a la fase superior $4 \mathrm{ml}$ de cloroformo:alcohol isoamílico (24:1), se homogenizó por 1 minuto, y se volvió a centrifugar a $4^{\circ} \mathrm{C}$ por 5 minutos a $4000 \mathrm{RPM}$. A la fase acuosa se le añadió $400 \mu \mathrm{l}$ de acetato de sodio $3 \mathrm{M}$ y $8 \mathrm{ml}$ de etanol absoluto frío. Se dejó precipitar por 30 minutos 
y se centrifugó a $4^{\circ} \mathrm{C}$ por 30 minutos a 4000 RPM. Luego, se descartó el alcohol y disolvió el pellet con $4.5 \mathrm{ml}$ de agua estéril precalentada a $56^{\circ} \mathrm{C}$.Se añadió $1.8 \mathrm{ml}$ de bromuro cetiltrimetilamonio y después de 15 minutos de incubación a temperatura ambiente, se centrifugó a $25^{\circ} \mathrm{C}$ por 30 minutos a $4000 \mathrm{RPM}$. Se resuspendió el pellet en $150 \mu$ de solución salina $(\mathrm{NaCl} 1 \mathrm{M}), 30 \mu \mathrm{l}$ de acetato de sodio $3 \mathrm{M}$ y $900 \mu \mathrm{l}$ de etanol absoluto frío y se agitó por inversión. Luego, se precipitó por 30 minutos y se centrifugó a $4^{\circ} \mathrm{C}$ por 30 minutos a 4000 RPM. Se añadieron $500 \mu \mathrm{l}$ de etanol al $70 \%$ frío y se centrifugó a $4^{\circ} \mathrm{C}$ por 30 minutos a 4 000 RPM. El pellet final se secó y resuspendió en 100 $\mu l$ de agua estéril.

\section{Colección de muestras de agua del Río Sechura}

Se recolectó muestras de agua cada 15 días durante 4 meses (desde Mayo hasta Setiembre de 2013). Se estableció tres puntos de referencia para la toma de muestras: en el brazo sur de la bifurcación del río $\left(5^{\circ} 33^{\prime} 17.626^{\prime \prime} \mathrm{S}, 80^{\circ} 49^{\prime} 35.481^{\prime \prime} \mathrm{W}\right)$, luego en la zona central a nivel del puente del Río Sechura $\left(5^{\circ} 33^{\prime} 02.179^{\prime \prime} \mathrm{S}, 80^{\circ} 49^{\prime} 09.139^{\prime \prime} \mathrm{W}\right)$, finalmente en la bifurcación norte $\left(5^{\circ} 33^{\prime} 04.153^{\prime \prime} \mathrm{S}, 80^{\circ} 49^{\prime} 26.826^{\prime \prime} \mathrm{W}\right)$. El Río Sechura está ubicado en la provincia de Sechura, departamento de Piura, Perú.

Las muestras de agua fueron recolectadas a $1 \mathrm{~m}$ de profundidad. Para recoger la muestra se empleó una cuerda y un balde desinfectado con lejía al 7\%. Para el almacenamiento se utilizaron botellas de plástico rotuladas de 1 litro previamente esterilizadas (20 minutos a $121^{\circ} \mathrm{C}$ ), las cuales fueron transportadas con hielo para su análisis en el laboratorio de Biología Molecular de la Facultad de Medicina Veterinaria y Zootecnia de la Universidad Peruana Cayetano Heredia en Lima.

\section{Extracción del ARN viral}

Para purificar el ARN viral en agua concentrada se usó el kit comercial rnEASY PLANT MINIKIT (Qiagen, Alemania) de acuerdo al protocolo del fabricante. Brevemente, primero, se colocó $100 \mu \mathrm{l}$ de muestra de agua concentrada, se agregó $450 \mu \mathrm{l}$ de buffer RLC y se homogenizó por 15 segundos. Luego, se transfirió a una columna spin QIAshredder, se centrifugó por 2 minutos a máxima velocidad y el sobrenadante fue transferido a otro cono limpio donde se añadió $200 \mu \mathrm{l}$ de etanol al 100\%. Después de esto, se transfirió la muestra a una columna mini spin RNeasy y se centrifugó usando una centrífuga (Hettich, Alemania) a 8000 RPM por 15 segundos. Luego, se añadió $700 \mu$ de buffer RW1, se centrifugó a 8000 RPM por 15 segundos. A continuación, se añadió $500 \mu \mathrm{l}$ de buffer RPE, y se centrifugó a 8000 RPM por 15 segundos. Posteriormente, se añadieron $500 \mu 1$ de buffer RPE y se centrifugó a 8000 RPM por 2 minutos. Seguidamente, la columna se colocó en un tubo nuevo y se centrifugó a máxima velocidad por 1 minuto. Finalmente, se volvió a colocar la columna en un tubo nuevo y se agregaron $40 \mu$ de agua libre de ribonucleasa (RNasa) y se centrifugó a 8000 RPM por 1 minuto. Las muestras extraídas se conservaron a $-20^{\circ} \mathrm{C}$.

\section{Detección de la presencia de VHA por RT-PCR en tiempo real}

Para el PCR, se usó el kit QuantiTecProbe RT-PCR (Qiagen, Alemania). Para cada corrida, se preparó el master mix en hielo, de acuerdo al protocolo de fabricante obteniendo un volumen final de $25 \mu \mathrm{L}$ (12.5 $\mu \mathrm{L}$ de buffer, $1.25 \mu \mathrm{L}$ de primer forward, $2.25 \mu \mathrm{L}$ de primer reverse, $0.25 \mu \mathrm{L}$ de probe, $0.25 \mu \mathrm{L}$ de enzima, $3.5 \mu \mathrm{L}$ de agua y $5 \mu \mathrm{L}$ de la muestra de ARN). Los primers usados fueron los asignados por el Comité Europeo de Normalización: 5'-TCA CCG CCG TTT GCC TAG-3 como forward, 5' GGA GAG CCC TGG AAG AAA G-3' como reverse y FAM-5'-CCT GAA CCT GCA GGA ATT AA-3' como sonda. Como blanco, se añadió agua en vez de muestra y como control positivo se añadió ARN extraído de heces de personas serológicamente positivas a Hepatitis A. El programa de corrida en el LightCycler Nano (Roche, Alemania) tuvo un paso inicial a $50^{\circ} \mathrm{C}$ por 30 minutos, $95^{\circ} \mathrm{C}$ por 15 minutos, y para la amplificación se programaron 45 ciclos de $95^{\circ} \mathrm{C}$ por 15 segundos, y $60^{\circ} \mathrm{C}$ por 1 minuto.

\section{Análisis de datos}

Los datos obtenidos del RT-PCR en tiempo real fueron automáticamente procesados por software del equipo LightCycler Nano (Roche, Alemania), el cual envió los datos de Ciclo de Cuantificación $(\mathrm{Cq})$ para la cuantificación viral de cada muestra. Los resultados se expresaron como positivo o negativo.

\section{Curva de referencia}

Las muestras positivas se procesaron nuevamente para cuantificarlas mediante una curva de referencia. Esta curva se elaboró usando un cultivo de VHA 
donadas por el Laboratorio de Biología Molecular de la Universidad de Barcelona, con una concentración inicial de 4.4 x 10-7 TCDI 50/ $\mathrm{ml}$, de la cual se prepararon cuatro diluciones.

\section{Verificación del proceso de concentración de virus en agua}

Se realizaron dos ensayos con inoculaciones de 300 $\mathrm{mg}$ y $70 \mathrm{mg}$ de heces positivas a VHA por RT-PCR en tiempo real en $40 \mathrm{ml}$ de agua de río. Se continuó con el proceso de concentración de virus en agua según lo detallado anteriormente en esta sección, seguido de la extracción de ARN y el RT-PCR en tiempo real.

\section{RESULTADOS}

El diagnóstico de cuatro niños con suero positivo a ELISA Hepatitis A fue confirmado mediante RTPCR en tiempo real en muestras de heces. Logrando el $100 \%(4 / 4)$ de resultados positivos.

El RT-PCR en tiempo real de los 2 ensayos (70 y $300 \mathrm{mg}$ de heces) para la verificación del proceso de concentración de virus en agua resultaron positivas.
Dos muestras de agua del río Sechura analizadas resultaron positivas a VHA por la prueba de RT-PCR en tiempo real. El resto de las muestras no presentó amplificación para el virus, considerándose negativas (ver Cuadro 1).

Se obtuvo 612,032.10 copias de ARN/L (Cq: 27.7) y 791,893.42 copias de ARN/L (Cq: 27.4) de la cuantificación de las muestras positivas a partir de la curva de referencia (Cuadro 2).

\section{DISCUSIÓN}

Los resultados obtenidos durante este trabajo, indican una irregular presencia del virus de Hepatitis A en el agua de río, las muestras detectadas como positivas, corresponden a la toma del 7 de Junio del 2013 en la zona sur y norte del río. Sin embargo, la muestra tomada del puente de la misma fecha, no presentó positividad. Esto nos señala que un solo muestreo para una fecha no es suficiente para saber si está contaminado el río o no. En los tres puntos de muestreo se detectó presencia de basura de diferentes orígenes, domestica, desmonte y también residuos de pesca y maricultura. Además, las muestras positivas se dieron el 7 de junio del

Cuadro 1. Resultados del RT-PCR en tiempo real para las muestras de agua del Río Sechura de Mayo a Setiembre del 2013.

\begin{tabular}{|c|c|c|c|c|c|c|c|c|}
\hline Punto de & & & & Fecha de & muestreo & & & \\
\hline Muestreo & 14-may & 07-jun & 21-jun & 05-jul & 19-jul & 09-ago & 23-ago & 13-sep \\
\hline $\mathrm{N}$ & Ausencia & Presencia & Ausencia & Ausencia & Ausencia & Ausencia & Ausencia & Ausencia \\
\hline $\mathrm{P}$ & Ausencia & Ausencia & Ausencia & Ausencia & Ausencia & Ausencia & Ausencia & Ausencia \\
\hline S & Ausencia & Presencia & Ausencia & Ausencia & Ausencia & Ausencia & Ausencia & Ausencia \\
\hline
\end{tabular}

Punto de muestreo en la rama norte (N), punto de muestreo en el puente (P) y punto de muestreo en la rama sur (S) del Río Sechura.

Cuadro 2. Cuantificación de la carga viral seriada en

muestras positivas a VHA

\begin{tabular}{llll}
\hline $\begin{array}{l}\text { Curva de Referencia } \\
\text { VHA }\end{array}$ & $\mathbf{C q}^{\mathbf{a}}$ & $\begin{array}{l}\text { Cuantificación } \\
\text { Copias de ARN/L }\end{array}$ \\
\hline & & & \\
1 & $44,000,000$ & 22.3 & $46,567,905.09$ \\
2 & $4,400,000$ & 25.3 & $4,809,227.36$ \\
3 & 440,000 & 28.9 & $318,672.04$ \\
4 & 44,000 & 31.4 & $51,199.55$ \\
5 & 4,400 & 34.6 & $4,513.27$
\end{tabular}

\section{Muestras Positivas}

\begin{tabular}{lll}
6 & 27.7 & $612,032.10$ \\
7 & 27.4 & $791,893.42$ \\
\hline
\end{tabular}


Figura 1. RT-PCR en tiempo real de muestras positivas. Muestra del 7 de junio del punto norte del Río Sechura (Roja).Muestra del 7 de junio del punto sur del Río Sechura (Verde). Control positivo, heces (Morado). Control negativo (Celeste).

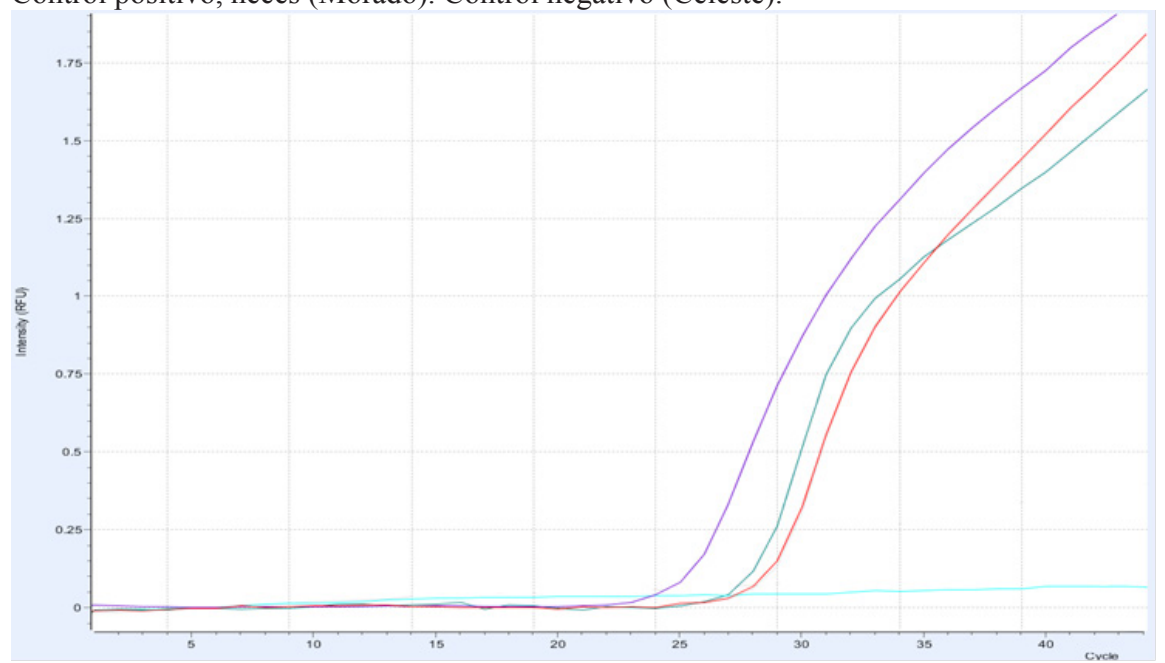

2013 cuando la época de lluvias había finalizado y la temperatura ambiental oscila entre los 16 a $29{ }^{\circ} \mathrm{C}$.

El porcentaje de muestras positivas es mayor a los reportados por (Borchardt et al., 2004) en el Río Negro, EEUU (0/12, 0\%) y por (Kittigul et al., 2005) en un río de Bangkok, Tailandia $(0 / 10,0 \%)$. Nuestros resultados fueron más bajos que los encontrados por (Taylor et al., 2001) en el Río Klip, Sudáfrica (18/51, $35.3 \%$ ); por (Pina et al., 2001) en el Río Llobregat $(22 / 56,39.5 \%)$ y en el Río Ter (2/10, 20\%) en España; y por (De Paula et al., 2007) en el Río Negro, Brasil (48/52, 92\%). La cuantificación de la carga viral de las muestras positivas $(612,032.10 \mathrm{c} / \mathrm{L}$ y $791,893.42 \mathrm{c} / \mathrm{L})$ fueron más elevadas que las obtenidas por (Pina et al., 2001) en el Río Llobregat (100 c/L) y en el Río Ter $(10$ c/L) en España; por (Rose et al., 2009) en el Gran Canal, Venecia (730 c/L); y por (De Paula et al., 2007) en el Río Negro, Brasil (5,500 c/L).

E1 Río Sechura tuvo presencia de VHA en sus aguas en junio del 2013, por lo que es un riesgo para la salud de la población. El río es contaminado constantemente por desagües, colectores, y residuos industriales; y ponen en peligro la salud de las personas aledañas al río, siendo los niños los más propensos por tener menos hábitos de higiene. Cuando ocurren infecciones de VHA en jóvenes y en adultos representa una carga económica muy importante para la sociedad debido a que deben parar con sus actividades de trabajo.

Desde el punto de vista socio-económico, la presencia de VHA en el agua de Río Sechura representa un riesgo potencial para todas las actividades que se desarrollan en su entorno, de la misma forma se ve afectada la bahía de Sechura, uno de los principales centros de repoblamiento y cultivo de moluscos bivalvos (Cavero y Rodríguez 2008).

Por otro lado, la Unión Europea decidió ampliar la fecha de suspensión de las importaciones de moluscos bivalvos frescos o congelados hasta 30 de noviembre del 2014, debido a la falta de garantías proporcionadas por las autoridades peruanas (2013/636/UE). Este trabajo de investigación confirma la presencia de VHA en el río, el mismo que afectará a la bahía. Durante las semanas de muestreo se pudo observar como los pobladores contribuyen a la contaminación del río. La ex-ministra de producción, Gladys Triveño, señaló en el diario El Comercio (Sección B9, 14 de diciembre de 2012), que las que las pérdidas económicas por no exportar bivalvos desde el 2008 hasta el 2012 alcanzaban los US\$ 391 millones.

En este sentido, es necesario que las autoridades tomen medidas como ejecutar obras de ingeniería que garanticen la recolección y tratamiento de las aguas servidas que actualmente se descargan directamente al río; informen, coordinen y formen en valores ambientales a la población en colegios y campañas así como también a los pescadores. Por otro lado, repetir este estudio en otros puntos del Río Sechura sería conveniente para determinar el origen de la contaminación. En Venezuela, se planteó un proyecto de saneamiento el Río Guayre, que buscaba acondicionar los drenajes, fortalecer la participación social y comunitaria mediante la educación ambiental, en el 2012. Javier Asín Semberoiz, Director gerente del Centro de Recursos Ambientales de Navarra, en 
el 2013 califica la participación ciudadana como fundamental en la resolución de los conflictos y problemas ambientales en general, y del agua y de los ríos, en particular. Sin olvidar otras actividades de carácter educativo y de participación como el voluntariado.

En sucinto, los resultados positivos a HAV en muestras de agua del Río Sechura ponen en riesgo a la población en los aspectos sanitaria, social y económica por lo que es necesario que las autoridades tomen medidas pronto.

\section{Correspondencia}

Armando Hung

Armando.Hung@upch.pe

\section{AGRADECIMIENTOS}

Los autores agradecen el aporte económico del proyecto FIDECOM PIPEA 090-2011 y de la beca Bárbara Ann Kotowski de Tejada. También a María Esquivel del Instituto Nacional de Salud del Niño por facilitar los controles positivos.

\section{BIBLIOGRAFIA CITADA}

1. [OMS] Organización Mundial de la Salud. 2008. Hepatitis A. Organización Mundial de la Salud. Nota Descriptiva $\mathrm{N}^{\circ} 328$.

2. Cuthbert J. 2001. Hepatitis A: Old and New. Clin Microbiol Rev 14: 38-58.

3. Restrepo J, Toro A. 2011. Hepatitis A. MedLab 17: 11-22.

4. Pintó R, Costafreda M, Bosch A. 2009. Risk assessment in shellfish-borne outbreaks of Hepatitis A. Appl Environ Microbiol 75(23): 7350-7355.

5. Rose M, Dhar A, Brooks H, Zecchini F, Gersberg R. 2006. Quantitation of hepatitis A virus and enterovirus levels in the lagoon canals and Lido beach of Venice, Italy, using real-time RT-PCR. Water Res 40: 23872396.

6. Taylor M, Cox N, Very M, Grabow W. 2001. The occurrence of Hepatitis A and astroviruses in selected river and damn waters in South Africa. Water Res 35: 2653-2660.

7. De Paula V, Dinix-Mendes L, Villar L, Luz S, Silva L, Jesús M. 2007. Hepatitis A virus in environmental water samples from the Amazon Basin. Water Res 41:1169-1176

8. Ali M, Al-Herrawy A, El-Hawaary S. 2004. Detection of enteric viruses, Giardia and Cryptosporidium in two different types of drinking water treatment facilities. Water Res 38:3931-3939.
9. Kittigul L, Uthaisin A, Ekchaloemkiet S, Utrarachkij F, Luksamijarulkul P. 2005. Detection and characterization of Hepatitis A virus in water samples in Thailand. J Appl Microbiol 1100: 1318-1323

10. De Serres G, Cromeans T, Levesque B, Brassard N, Barthe C, Dionne M. 1999. Molecular confirmation of hepatitis A virus from well water: epidemiology and public health implications. J Infect Dis 179:3743.

11. Gregory J, Litaker R, Noble R. 2006. Rapid onestep quantitative reverse transcriptase PCR assay with competitive internal positive control for detection of Enteroviruses in environmental samples. Appl Environ Microbiol 72: 3960-3967.

12. Atmar R, Neill F, Romalde J, Le Gutader F, Woodley C, Metcal T. 1995. Detection of Norwalk virus and Hepatitis A in shellfish tissues with the PCR. Appl Environ Microbiol 61: 3014-3018.

13. Da Silva A, Le Saux J, Parnaudeau S, Pommepuy M, Elimelech M, Le Guyader F. 2007. Evaluation of removal of noroviruses during wastewater treatment, using real-time reverse transcription-PCR: Different behaviors of genogroups I and II. Appl Environ Microbiol 73(24): 7891-7897.

14. Tsai Y, Sobsey M, Sangermano L, Palmer C. 1993. Simple method of concentrating enteroviruses and Hepatitis A virus from sewage and ocean water for rapid detection by reverse transcriptase-polymerase chain reaction. Appl Environ Microbiol 59:34883491.

15. Cavero P, Rodríguez P. 2008. Producción sostenida de moluscos bivalvos en el Perú: acuicultura y repoblamiento. En: Lovatelli A, Farías A, Uriarte I. Estado actual del cultivo y manejo de moluscos bivalvos y su proyección futura: factores que afectan su sustentabilidad en América Latina. Puerto Montt, Chile. FAO 12: 209-218.

16. Acuña J, Vera A, Yerren S, Ordoñez G. 2006. Atlas hidrológico de las cuencas Chira y Piura ubicados en el departamento de Piura. SENAMHI.

17. Borchardt M, Haas N, Hunt R. 2004. Vulnerability of drinking-water wells in La Crosse, Wisconsin, to enteric-virus contamination from surface water contributions. Appl Environ Microbiol 70:59375946.

18. Pina S, Buti M, Jardí R, Clemente-Casares P, Jofre J, Girones R. 2001. Genetic analysis of Hepatitis A virus strains recovered from the environment and from patients with acute hepatitis. J Gen Virol 82:2955-2963.

Recibido: $16 / 04 / 2014$ Aceptado: 21/05/2014 